\title{
Ramsay Hunt syndrome: an uncommon presentation in an immunocompetent patient
}

Ramsay Hunt syndrome (also known as herpes zoster oticus) is a reactivation of latent varicella zoster virus at the level of sensitive cells of geniculate ganglion (of facial nerve), in patients with previously documented infection. This syndrome is characterized by the presence of cutaneous facial lesions associated with peripheral facial paralysis, severe ear pain and small blisters on the outer ear or in the mouth. Other frequent complaints are nauseas, vertigo and nystagmus, these symptoms were explained by the close proximity of the geniculate ganglion to the vestibulocochlear nerve within the bony facial canal. It is estimated to account for $18 \%$ of facial palsies in adults. It has a good prognosis when early therapy is introduced.

We present the case of a male patient of 77 years old, immunocompetent, observed in an emergency department due to inflammatory signs on the outer right ear and face, associated with otalgia, otorrhea, and homolateral erythematous-vesicular cutaneous rash, with 2 days of evolution and that conditioned facial weakness. The patient had history of herpes zoster infection in the childhood and recurrent labial lesions due to varicella zoster virus infection.

On physical exam, the patient reported severe pain complaints since the onset of the rash, with right facial paralysis. He presented with erythematous vesicles in the external auditory meatus, in the right auricle and right face (Figures 1 and 2). In neurological examination, besides the asymmetry of the face, it presented an exhaustible horizontal nystagmus in the extreme position of the eyes to the right. Analytically, there was mild leukocytosis $\left(9.1 \times 10^{\%} / \mathrm{L}\right)$ and elevated C-reactive protein $(2.95 \mathrm{mg} / \mathrm{dL})$ with increased erythrocyte sedimentation rate $(33 \mathrm{~mm} / \mathrm{h})$. The patient underwent cranioencephalic computed tomography scan, which confirmed the facial cellulitis without evidence of abscessed lesions.

The patient was treated with intravenous corticosteroid (40mg, bid) and acyclovir (800mg, 5 times daily), for 7 days. Potassium permanganate (topic application, 3 times daily) and gabapentin (300mg, bid) were subsequently associated during hospitalization. Concerned with superinfection of the subcutaneous tissues of the face, cefoxitin was initiated (1g, 3 times daily, 7 days). The patient had gradual improvement (with full recovery), having been discharged after 7 days of hospitalization, medicated with gabapentin $300 \mathrm{mg}$ bid.

This clinical case is particularly interesting because Ramsay Hunt syndrome is a rare complication of herpes zoster with reactivation of latent varicella zoster virus infection and it is the second most common cause of atraumatic peripheral facial paralysis. Diagnosis was possible due to high degree of suspicion and the exuberance of complaints. The syndrome

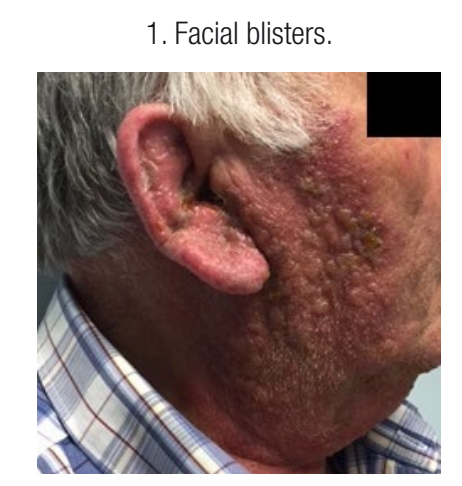

2. Ear and facial lesions.

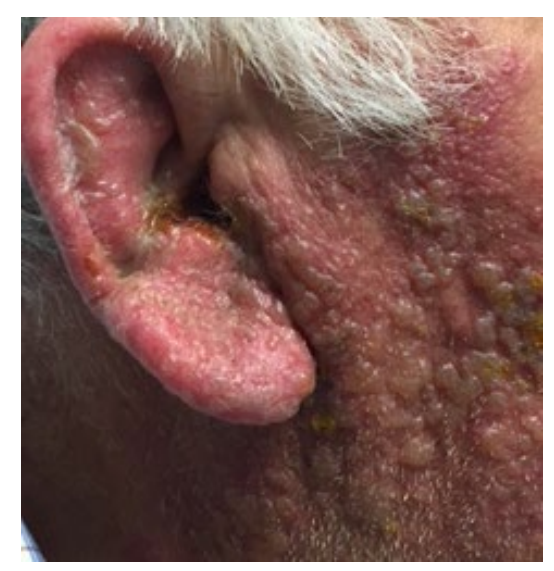

itself is not contagious, however, the herpes zoster virus that can be found in the blisters of Ramsay Hunt syndrome can be transmitted. Early intervention, with antivirals and corticosteroids, is essential in these cases for complete reversal of complaints.

Acknowledgment: Dr. Amílcar Silva, Prof. Dr. Adriano Rodrigues Serviço de Medicina Interna B, Hospital Geral do Centro Hospitalar e Universitário de Coimbra

\section{Bibliography}

1. Worme M, Chada R, Lavallee L. An unexpected case of Ramsay hunt syndrome: case report and literature review. BMC Research Notes. 2013;6:337.

2. Yoon KJ, Kim SH, Lee EH, Choi JH. Disseminated Herpes Zoster in an Immunocompetent Elderly Patient. The Korean Journal of Pain. 2013;26(2):195-198.

3. Mahfoudhi M, Lahiani R. Syndrome de Ramsay Hunt. The Pan African Medical Journal. 2015;22:171.

4. Sweeney C, Gilden D. Ramsay Hunt syndrome. Journal of Neurology, Neurosurgery, and Psychiatry. 2001;71(2):149-154.

\section{Diagnosis: Ramsay Hunt syndrome}

Joana Cascais Costa, Cátia Pereira

Serviço de Medicina Interna B, Hospital Geral do Centro Hospitalar e Universitário de Coimbra 